Article

\title{
What Role Do Disaster Victims Play as the Mainstream for Future Disaster Preparedness in Korea? Case Studies of Foundations Established by Disaster Victims
}

\author{
Seol A. Kwon ${ }^{1, *}$ and Sang Il Ryu ${ }^{2}$ \\ 1 National Crisisonomy Institute, Chungbuk National University, Chungbuk 28644, Korea \\ 2 Department of Fire Administration and Disaster Management, Dong-Eui University, Busan 47340, Korea; \\ samuel@deu.ac.kr \\ * Correspondence: seolakwon@chungbuk.ac.kr
}

Received: 25 August 2020; Accepted: 8 October 2020; Published: 14 October 2020

\begin{abstract}
Historically, the primary agents performing key roles in disaster preparedness, as well as risk mitigation and vulnerability reduction, in Korea have been the central government, local government, and regional government. Recently, and without controversy, the disaster management paradigm has shifted from disaster relief to disaster preparedness, risk mitigation, and vulnerability reduction. This study examines case studies in an effort to document the integral roles that direct victims and their families have played in disaster preparedness. The success of the Foundation for Disaster Preparation, established by survivors of disasters, is analyzed through a framework using media interviews. The results of this study demonstrate that disaster survivors and bereaved families play significant roles as primary agents in the effective management of various regeneration projects as well as in the strengthening of resilience after disasters. As the case studies show, legitimate disaster victims are more informed concerning the requirements for disaster management because they have experienced first-hand the trauma caused by a disaster and its aftermath. These subdivided activities are expected to provide assistance by characteristics of local governments, types of disasters, and targets.
\end{abstract}

Keywords: disaster survivors; disaster preparedness; resilience; vulnerability; crisis management; disaster management; disaster victims; bereaved families; foundation

\section{Introduction}

Disaster occurs in various forms, such as earthquakes, floods, storms, heat waves, tsunamis, and epidemics, posing a grave threat to peace and security in terms of human life, economic development, and ecological diversity worldwide. In March 2019, Cyclone Idai hit Mozambique, Zimbabwe, and Malawi, causing massive damage to communities, infrastructure, and agricultural land. This not only has dealt a major setback to the development of these countries but could potentially trigger long-term social and political instability (Akter and Wamba 2019; Prior and Roth 2019).

Since 2000, the number of disasters and the extent of their damage have increased significantly, causing extensive casualties and threatening people's livelihoods. This has brought about a paradigm shift in disaster management from disaster relief to disaster preparedness, risk mitigation, and vulnerability reduction. Historically, the primary agents performing the key roles in disaster preparedness, as well as risk mitigation and vulnerability reduction, have been nations' central, local, and regional governments (Hidayat and Egbu 2010). 
Discussions on disaster resilience have intensified since the 2005 World Conference on Disaster Reduction held in Kobe, Hyogo, Japan. Specialists in the field identified the key to disaster resilience as focusing upon the ability of people and the community to cope with crises and disasters (Walter 2004; Manyena et al. 2011; United Nations Office for Disaster Risk Reduction 2005).

The Sendai Framework for Disaster Risk Reduction (SFDRR) 2015-2030, which was approved by the UN in 2015, is the second transnational attempt to improve national disaster management governance over the next 15 years. Its purpose is to enhance the resilience of local communities through horizontal/vertical cooperation between the government, the private sector, and non-profit organizations (United Nations Office for Disaster Risk Reduction 2020).

This is disaster risk governance, which is a key principle in the decision-making process for addressing the risk arising from disasters. It includes various actors who lead collective binding decisions to respond to the disasters and the processes accompanying them. The prerequisites for maintaining such national disaster management governance are the establishment of legal institutions and policies, development and support-advocacy groups, knowledge sharing, and communication, as well as securing means for broader participation (Tierney 2012; Rao 2013).

Disaster risk reduction in the Sendai Framework requires the participation and cooperation of all members of society. This requires inclusive, accessible, and undifferentiated participation. Attention should be paid especially to those who suffer significantly from disasters (United Nations Office for Disaster Risk Reduction 2020).

In particular, disaster risk reduction and management both rely on a cooperative system between sectors and require cooperation among the stakeholders of all sectors. Further, they require participation of administrative and legislative bodies at the national and regional levels of all countries. Efforts are required to ensure interaction, cooperation, and complementarity capability in terms of sharing the roles and responsibilities through the distribution of responsibilities among private stakeholders, including business and academia, and public institutions (United Nations Office for Disaster Risk Reduction 2020).

According to a study by Tiepolo and Braccio (2020), public participation is emphasized in accordance with the Sendai Framework for Disaster Risk Reduction (DRR) in rural Africa, and national guidelines are highly connected to the participation of local residents. A study by Goniewicz and Burkle (2019) also argues for strengthening the governance for disaster risk reduction by introducing the purpose of the Sendai Framework into the community in Poland.

The resilience of a local community in disaster recovery and alleviation of environmental risks is a highly crucial factor (Wilkin et al. 2019). According to Goidel et al. (2019), a community's participation, resilience, and construction activities are significant output factors for the community to be prepared for risks. Moreover, as modern disasters continue to increase in number and scope, they will undoubtedly affect a greater number of people, thus making it essential to understand long-term disaster recovery.

Trauma experienced by individuals and families due to extensive disasters brings anxiety, depression, drug abuse, violence, and alienation (Catherall 2004; Denborough 2006; Webb 2003). Specifically, trauma suffered by individuals and families causes them to experience secondary mental shock and compassion fatigue in many cases (Figley and McCubbin 1983). Moreover, as debilitating emotions and harmful behaviors continue, victims suffer continued pain through ongoing experience of the disaster. This causes families and the entire community to experience the effects of collective trauma. Specifically, the complex, ongoing, or repeated trauma experienced by people living in the area of a disaster scene may undermine the function of families and the important network of kinship. Therefore, in nearly all therapeutic approaches, observing the disaster resilience of families and the local community is essential to overcome a critical trauma. Furthermore, the family and community network may also be an essential resource for disaster recovery when their strengths and potential are unified (Walsh 2007).

Experts and first responders in the private sector can perform a key role in facilitating community resilience in the face of future disasters. This is because we can accurately grasp the actual needs 
and demands that it is not possible to fulfill in the public domain. They also have direct and indirect experience in disasters, so their responsiveness is stronger. In addition, survivors and bereaved families who have already experienced such disasters have a better understanding than anyone of what should be done and by whom and can thus help maximize disaster resilience (Alexander and Klein 2009).

Specifically, when disasters cause extreme and extensive property damage or continuous financial issues for the affected community, they correlate to a high level of trauma such as violence, injuries, threats to and loss of life, harm related to corruption, and unhealthy relationships between business and politics. Immense material and psychological damage are experienced by disaster survivors and bereaved families due to disparate social structures. In addition, they experience posttraumatic stress for an extensive period of time following the disaster (Norris et al. 2002a).

This study aims to examine the role of disaster survivors and bereaved families in disaster preparedness in Korea, based on case studies of successful networks that can serve as essential resources for disaster resilience. In particular, the study provides the same context as the one espoused by the international community in the Sendai Framework, which is to enhance the resilience of the local community through horizontal/vertical cooperation between non-profit organizations.

These case studies focus upon three major disasters that occurred in Korea (the Sealand fire, the Daegu subway fire, and the Sewol ferry disaster) and the successful efforts of nonprofit organizations (NPOs) founded by the disaster survivors and bereaved families from these disasters to support disaster preparedness and recovery. Information was gathered through an examination of media interviews, secondary sources, and the roles and activities of the NPOs. Interview data were collected from interviews by major media and newspapers from 16 April 2014 to 30 January 2020, with the first case from 30 June 1999 to 30 January 2020, and the last case from 18 February 2003 to 30 January 2020. Items searched for included victim names, victim interviews, and post-accident interviews.

\section{Theoretical Discussions}

\subsection{Primary Agents of Disaster Preparedness}

The local government's role in disaster preparedness has become more important. Authorities who believe in alleviating the impact of a disaster consider the most important goals of disaster planning to be prompt measures and effective restoration. The regional jurisdiction must regard the concept of resilience as an essential part of disaster preparedness. Resilience relies upon infrastructure, operations, and the capacity of social systems to respond to and recover from extreme events. A restoration system reduces the probability and outcomes of failure (such as deaths, injuries, physical damage, and negative economic and social impacts) as well as recovery time (Government Finance Officers Association of the United States and Canada 2008).

In mass casualty incidents, sometimes the community may not receive assistance from the central government for a few hours or even a few days. The local government must take the lead in protecting its citizens through disaster risk assessment, decision-making, operation, information sharing, and communication (Col 2007; Khan 2008).

Because the local government performs the most active part in disasters, its role and competency requirements are important. Protecting the community from disaster vulnerability and reducing damage caused by disasters are the local government's responsibilities during disaster preparedness (Kusumasari et al. 2010; Bajracharya et al. 2011; Ross 2013).

Disaster survivors and bereaved families comprise victims and their families who were personally affected by the disaster. Their needs play a key role in recovering from disasters and in preventing and preparing for similar disasters. According to a study of disaster survivors by Norris et al. (2002b), survivors experience specific psychological problems, such as unspecified pain, health issues, chronic problems in everyday life, and loss of resources. All of these may be exacerbated in young people based on the degree to which they experience disasters. Among women, middle-aged and elderly people, 
and minority groups, secondary stress factors from disasters, previous mental illnesses, and weak or deteriorating mental and social resources cause an increase in the possibility of negative outcomes.

Moreover, according to Mishra and Suar (2007), disaster survivors and bereaved families that have experienced disasters have a higher risk perception and are more prepared for disasters than the general public and individuals who have not experienced one. In addition, Onuma et al. (2017) proved that people who have experienced the devastation of a disaster are more fully prepared for one, whereas residents and regions without experience lack preparedness due to lower perception of risk.

\subsection{Disaster Preparedness Framework of Disaster Survivors and Bereaved Families as the Main Agents}

When a disaster occurs and creates disaster survivors and bereaved families, it results in psychological and physical damage, economic loss, and social ostracism (alienation). First, psychological trauma is a typical symptom of posttraumatic stress disorder (PTSD) that can occur in disaster survivors and bereaved families (Korol et al. 1999; Adams and Boscarino 2006; Yule et al. 2000; North et al. 2004; Alfonso 2018; Piccardi et al. 2016). Kiliç et al. (2003) demonstrated that disasters affect the entire family and that symptoms experienced by specific members of the family may cause secondary psychological shock to other members, especially children. Specifically, the research findings documented that both children and parents self-report PTSD, depression, and anxiety and received assessment from trained psychiatrists and psychologists up to 6 months after an earthquake.

Second, physical damage occurs in various forms, from bruises and bone fractures to death. According to Mohebbi et al. (2008), the December 2003 earthquake that occurred in Iran caused approximately 12,000 injuries, most of which (25\%) were lower extremity fractures. Moreover, physical damage may also lead to acquired physical disabilities. Some examples are not being able to walk or getting a chronic disease (Beck and Franke 1996; Reinhardt et al. 2011; Hemingway and Priestley 2006).

Third, economic loss leads to difficulty in making a living (Alexander et al. 2006; Joakim and Wismer 2015; Masud-All-Kamal 2013), housing issues due to damaged residences (Dhara and Acquilla 2012; Johnson 2007; Ollendick and Hoffmann 1982), and discontinued studies for students because their families can no longer afford to pay their tuition (Achoka and Maiyo 2008; Mudavanhu et al. 2015).

Fourth, disaster survivors and bereaved families face a great sense of alienation due to lack of communication with the government. Piccardi et al. (2016) claims that disaster victims' perception about institutional trust may affect the potential for healing. In particular, Piccardi et al. (2016) assessed the relationships between institutional trust, current psychological pain, social support, and satisfaction with life. Among the victims, low institutional trust was related to mental health problems, poor social support, barriers in seeking social support, and low satisfaction with life. Trust lost due to the aftermath of the disaster will likely never be regained, and lack of trust may cause health to deteriorate or become difficult to maintain. Moreover, Akbar and Aldrich (2017) confirmed through previous studies the importance of investing in nation-citizen social relations and the diversity of trust concerning post-disaster situations.

Specifically, alienation is caused by human relations within the community as well as the lack of related support services. Shaw and Goda (2004) stated that, as a result of the Kobe earthquake in Japan, the polarization of industries, employment, and community rebuilding has expanded, and both individuals and the community failed to recover from the shock of the earthquake. The only way to revive the community was to achieve socioeconomic rehabilitation at the individual level and to rebuild the destroyed community. A great deal of effort and support was needed for rebuilding, but this must be achieved not just by public administration but with the cooperation of the community, victimized residents, and related non-governmental organizations (NGOs) and NPOs. 
Prewitt Diaz (2018), Goreham et al. (2017), Lin et al. (2017), Gibbs et al. (2019), Marsh et al. (2017), and Lin (2018) consistently note the social bond within the community in relation to disaster recovery, mentioning volunteers flowing in from neighboring communities, services and materials provided by the local government and religious organizations, and financial support from federal agencies. Moreover, they suggest that a combination of resources derived from the experiences and perceptions of disaster victims, survivors, and bereaved families is key to disaster recovery.

In Korea, there were many cases in which the victims and bereaved were ridiculed and criticized after a major catastrophe, increasing social ostracism and alienation. Around the time of the Sewol ferry disaster in 2014, there were strikes and protests to ridicule the victims by eating food near the place where the bereaved were on a hunger strike (Park 2019). A YouTube channel was established to mock the Daegu subway disaster (Kim 2019), and disaster survivors and bereaved families were also disregarded by the government and the National Assembly (Yoon 2019).

Hikichi et al. (2020) systematically reviewed whether social capital at the community level could alleviate the side effects of natural disasters on cognitive reduction in the aftermath of the Great East Japan Earthquake and Tsunami in 2011. The research demonstrates that unofficial socialization and social participation at the community level minimize the effect of housing damage on mental health in the aftermath of natural disasters. This suggests that moving residents in with other members of the community helps preserve the social capital of the community and improve the cognitive resilience of older survivors.

In addition to the physical and psychological damage caused by a disaster, ostracism from society and political circles motivates the victims to strengthen their roles in order to protect themselves and their families from disasters (Raphael 1986; Paton 2006; Abramson et al. 2010).

\subsection{Disaster Preparedness and Community Reconstruction Efforts of the General Public and Disaster Victims} and their Families.

There are differences in disaster preparedness and community reconstruction efforts between the general public and disaster victims and their families.

There is a difference between the levels of disaster perception of disaster victims, their families, and the general public, depending on whether they have experienced disasters. The experience of a disaster plays a particularly pivotal role in the level of disaster preparedness. According to studies by Shapira et al. (2018), Cui and Han (2019), and Xu et al. (2020), disaster experience is an important variable in risk perception, which is an important predictor of future strategies for disaster preparedness.

Previous studies by Lo and Cheung (2016), Duan et al. (2020), and Lechowska (2018) show that disaster victims and their families generally make considerably more efforts to prepare for disasters than the general public do, showing a higher degree of risk awareness and readiness in response to future disasters (Figure 1).

In addition, disaster victims and their families have a higher sense of alienation from the community than members of the public who have not experienced general disasters. The results of an empirical analysis of 60,000 disaster victims from 1981 to 2001 by Norris et al. (2002a) showed that victims not only suffered mental and physical harm but also felt a sense of alienation and negative feelings toward their community. What is interesting here, however, is that negative and alienating feelings toward the community have a positive impact on community independence, restoration, and resilience. 

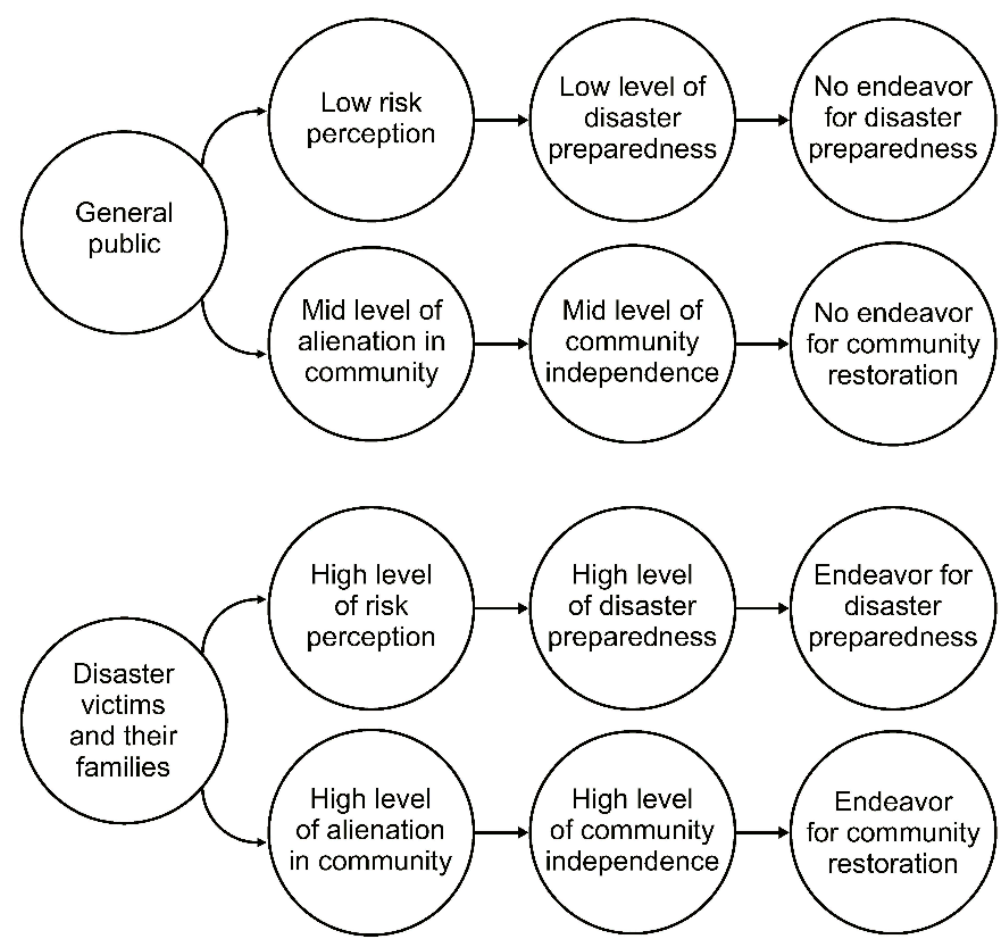

Figure 1. Roles of disaster victims and their families and the general public in disaster preparedness.

\section{Materials and Methods}

This study conducted and examined case studies in an effort to document the integral roles that direct victims and their families have played in disaster preparedness. In addition, the success of the Foundation for Disaster Preparation, established by the survivors, was analyzed through a framework using media interviews.

As the case studies show, disaster victims are more informed concerning the requirements for disaster management because they have experienced first-hand the trauma and aftermath caused by a disaster. In the case of a child victim, experience with disaster management is not extensive, thus, survivors work to ensure that children are more aware of how to prevent a disaster, such as fire prevention in the case of a fire disaster. In the case of the subway disaster, disaster management activities are centered on activities for transportation facility disasters. These subdivided activities are expected to provide assistance by characteristics of local governments, types of disasters, and targets.

The limitations of this study should be noted. Because this it is focused on Korea, the results might not be applicable to other countries and regions. Many factors determine the aftermath and impact of disasters on communities and greater populations. Additional studies in other regions and situations should be conducted to examine the roles of survivors and the bereaved in the aftermath of disasters.

\section{Results}

\subsection{Case Study 1: Hwaseong Sealand Fire (Korea Children Safety Foundation)}

The "Sealand Youth Training Center fire" was an incident that occurred on June 30, 1999 in 363-1, Baengmi-ri, Seosin-myeon, Hwaseong-si, Gyeonggi-do, Korea (Sealand Youth Training Center). According to the announcement made by the Korean National Forensic Service and Suwon District Prosecutor's Office, the incident was caused when mosquito repellent incense made contact with adjacent combustibles (a disposable gas lighter, paper, and clothing) and ignited. There were also administrative issues, specifically, the irresponsibility of the persons tasked with protective custody and care. Sealand Youth Training Center was built with inflammable materials like Styrofoam and 
wood as well as steel frame structures with high heat conduction, which also served as a factor for the major catastrophe (Kim 2006a).

Somang Kindergarten suffered the most significant damage, with 18 victims. A total of 42 children (18 in Room 301 and 24 in Room 302) were sleeping, while three adults, director Chun Kyung-ja, and two teachers were sleeping in Room 314 across from Room 301. The 18 children in Room 301 failed to escape the fire and died. Altogether, 553 persons and 67 facilities and equipment were mobilized to fight the fire (Kim 2006a).

The fire caused 29 casualties (23 deaths and 6 injuries) and property damage of KRW 72 million (goods KRW 10 million, real estate KRW 62 million) (Kim 2006a).

The collateral of the Sealand fire included the victims who lost their lives and the trauma suffered by the bereaved families. As revealed in the interviews, the trauma of the families that lost their children went on for an exceptionally long time.

\subsubsection{Risk Perception}

As illustrated in Figure 2, what pained the bereaved families the most in the Sealand disaster was their decision to trust the government agencies. The indifference and insincerity of government officials due to social alienation deteriorated the disaster resilience of the bereaved families, causing them to abandon their livelihoods and create a community of bereaved families (Kim 2006a).

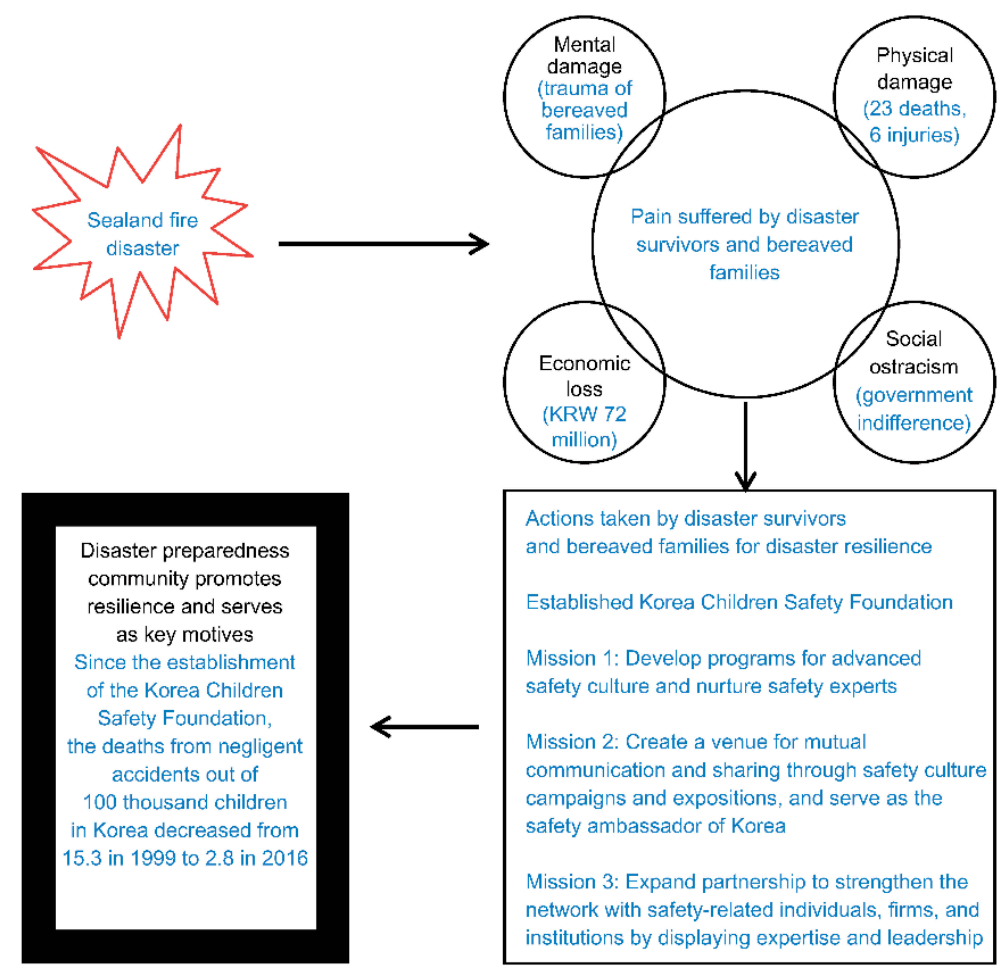

Figure 2. Disaster preparedness framework of disaster survivors and bereaved families for the Hwaesong Sealand fire.

After the accident, a father who had lost his son expressed his sorrow in a media interview:

"Whenever I feel depressed, I miss my son even more. This pain will only end when I die. My wife has been sick throughout the 18 years since the accident". (Hong 2017)

Another father who lost his children described his thoughts on the handling of the disaster through a media interview:

"I sometimes dream that the children just disappear and fall of the edge of the cliff.

The nightmares continue even after 15 years ... People around me say time heals all 
wounds, but it's not true ... [The pain of losing a child] is a pain a parent must bear forever and will only be cured after a lifetime of tears". (Lee 2014a)

"The government shifted the blame of fire onto the teachers and children who used the mosquito repellent incense and tried not to take responsibility. Some public officials even didn't hesitate to say that they want to sort this out quickly so that we won't leave a precedent (of compensation)". (Lee 2014a)

"Once the accident seems to be handled on the outside, it loses the interest of the government or officials in charge. The pain of losing family falls on the family in the end. And there was no psychotherapy for the bereaved families at the time. We had to visit doctors individually without the support from the central or local government. Psychotherapy or counseling was not even included in compensation". (Lee 2018)

"The investigation wasn't properly done on the public officials who permitted the illegal structure. I still can't help but feel doubtful that the government just closed the case quickly to prevent social criticisms over the government officials. We fought, claiming we couldn't have the funeral until they investigated and revealed the true facts of the case (funeral held after 38 days). We requested a face-to-face talk with the Prime Minister at the government building, and even planned to run a bus into the main gate". (Lee 2014b)

\subsubsection{Disaster Preparedness}

The Korea Children Safety Foundation was founded in 2000 with financial support from the bereaved families of the Hwaseong Sealand fire in Gyeonggi in 1999. Suk Ko, who was the representative of the bereaved at the time of the accident, quit his job and has since been serving as the foundation representative. "I think it's my mission to find anything I can do to create a world where children can be safe," said Ko (Go 2019).

"I couldn't say no when I was asked to be the representative of the bereaved families. I had to do it. The government wouldn't sort things out properly. At first the government didn't even clearly reveal the cause of fire and didn't properly punish the person who approved the illegal construction. So we set up this foundation led by the bereaved families to determine the cause of the disaster and prevent recurrence of the accident". (Lee 2018)

"We shouldn't leave such disasters to chance anymore. Children aren't being sacrificed because they're unlucky or they did something wrong. We must stop thinking that it's fine as long as me and my family avoid such accidents. In the end, disasters will be repeated unless we improve the general safety consciousness and system of our society". (Lee 2018)

"When the children were sacrificed by the fire, 'safety' was a word we weren't familiar with. But since the disaster, safety has become an inextricable and significant part of our lives". (Choi 2018)

"Other countries have special programs that help families who have suffered such major disasters or tragic incidents to overcome mental and physical pain and return to society. But in Korea, the victims or the bereaved families must struggle to determine the cause of the accident or find out the truth in the process of handling the disaster, which is really sad. That's why I think Korea also needs such institutional support". (KBS News 2015)

The interviews show that distrust in the government due to officials' indifference and insincerity after the Sealand fire motivated those affected to support disaster resilience. Therefore, the bereaved families established a foundation for disaster resilience to prevent similar disasters from happening again. 
After the incident, the Ordinance to Compensate the Victims of Hwaseong Sealand Youth Training Center Fire Incident was established on 21 March 2001 in order to console the victims and their families and to contribute to the stability of the community (Korea Children Safety Foundation 2017). As indicated by the interviews, this was not deemed enough of a response. Therefore, the parents of one of the disaster survivors and bereaved families established the Korea Children Safety Foundation in 2000 to improve children's safety culture after the incident. The Korea Children Safety Foundation conducts various safety education culture programs, R\&D projects, CSR (corporate social responsibility) activities, Seoul mobile safety experience classes, clear umbrella sharing for children's road safety, and infant car seat supply projects for children's safety (Korea Children Safety Foundation 2017).

As illustrated in Figure 2, the foundation performs policy research activities such as seminars, local and global data collection, and research to create a safe society based on safety policy research on children's disaster preparedness, while also developing and distributing guidelines for children, teachers, and guardians on each theme of safety (Korea Children Safety Foundation 2017).

Second, to avoid recurrence of disasters like the Hwaseong Sealand fire, the foundation carries out safety inspections of youth training centers to improve the centers and to create a safe environment for children. The foundation conducts safety inspections at over 200 training centers nationwide and surveys relevant staff on safety consciousness in order to actively design improvement plans and measures (Korea Children Safety Foundation 2017).

Third, the foundation provides activities for children vulnerable to disasters, such as safety inspections at welfare facilities for children with disabilities under the jurisdiction of the Ministry of Health and Welfare nationwide, with a focus on Seoul, Jeonju, and Ulsan. This project includes operating mobile safety education buses, distributing safety education materials for children with disabilities, and supplying safety devices such as fire extinguishers, safety helmets, and car footholds (Korea Children Safety Foundation 2017).

Fourth, the foundation offers post-disaster support programs for children affected by disasters. Children who suffered an incident or accident may severely alter the event in their minds as their cognitive ability or expressivity is not as developed. Thus, the foundation takes care of and manages children's and their families' mental pain (PTSD) until the children become adults, depending on their development and the severity of their experiences (Korea Children Safety Foundation 2017).

As such, the Korea Children Safety Foundation carries out various disaster preparedness programs for children's safety as a foundation established by the family of disaster survivors. These activities were introduced as best practices of safety culture in 2019 by the Ministry of Public Administration and Security and also received a citation from the Prime Minister, thereby proving their public confidence (Department of Safety Culture Education and Lee 2020). Since the establishment of the Korea Children Safety Foundation, the deaths from negligent accidents decreased from 15.3 out of 100,000 in Korea in 1999 to 2.8 in 2016 (Lee 2018).

\subsection{Case Study 2: Daegu Subway Fire (2.18 Foundation for Safety Culture)}

The "Daegu subway fire" occurred at 9:55 a.m. on Tuesday, 18 February 2003 on a subway inside Jungangno Station, Line 1 of Daegu subway in Namil-dong, Jung-gu, Daegu. It was caused by a passenger who committed arson. According to witnesses, the passenger started the fire when the subway was heading toward Ansim Station and pulled into Jungangno Station. The suspect opened the lid of a plastic paint thinner container on the seat to his right and lit a lighter; the fire started with a "boom." The suspect's clothes and seat cushions burst into flames and the fire spread quickly throughout the subway (Kim 2006b).

The fire caused 340 casualties (192 deaths and 148 injuries) and property damage of KRW 61.477 billion. Subway and Jungangno Station damages have been estimated to be: KRW 57 billion; subway, KRW 32.4 billion (train, KRW 18.8 billion, fare loss, KRW 13.6 billion); Jungangno Station, KRW 24.6 billion (facilities, KRW 23.1 billion, leased facilities in the station, KRW 1.5 billion); and damage to goods in nearby shops, KRW 4.477 million (Kim 2006b). Multiple problems were identified. First, 
there was a delay in evacuation time due to a long evacuation route $(160 \mathrm{~m}$ from the platform to the surface). There was also a lack of effective control of the massive amounts of smoke, poor evacuation due to limited visibility of emergency exit signs due to smoke, and difficulty in smooth evacuation due to a refuge barrier at the ticket gate. Moreover, there was failure to remove the cause of the incident due to a lack of public security officers in the station/tunnel/train. The train also used combustible interior materials such as FRP (fiber reinforced plastics), radiation crosslinked polyurethane, polyvinyl chloride resin, polyester, and urethane foam. The presence of these chemicals caused the fire to spread quickly. The presence of toxic gas made visual judgment impossible and increased casualties because of suffocation. There were also a failure in the first-aid firefighting due to poor recognition of fire extinguishers in the train and lack of initial fire extinguishing devices, poor initial response of the operator and subway control center, such as prohibiting the opposite-side subway from entering the station with fire that made it impossible for passengers to evacuate quickly, and lack of awareness of emergency escape through subway doors in the case of fire, which kept passengers from escaping quickly (Kim 2006b).

\subsubsection{Risk Perception}

The Daegu subway fire led to serious and long-lasting psychological trauma among the victims and bereaved families, as well as collateral financial implications due to the insufficient compensation system.

The disaster revealed a significant loophole in the emergency alert system of the subway, which caused excessive damage when the train coming from the opposite direction entered the station without stopping, despite the visibly large fire. Most casualties occurred on the train coming from the opposite direction, which caught fire, rather than from the one where the fire began. The operator of the approaching train evacuated the train and shut the doors down without realizing the effects, thereby sealing passengers inside. Once the blaze was contained, over 100 deceased victims were discovered inside the train (Kim 2006b).

Having lost his wife and daughter due to the Daegu subway fire in 2003, a husband said, "At the time, there wasn't even anything called psychotherapy. I knocked around not knowing what to do after the funeral at the time. People told me to let go, but is that possible? Of course, after a long time I don't think about my wife and daughter as much, but whenever there's a similar accident or I see beautiful clothes or stuff my wife used to use, it just breaks my heart. I was completely dazed during the funeral. I became so helpless afterwards and couldn't work for two years. I was always angry right after I lost my wife and daughter. I couldn't control my anger toward a trivial thing that a friend said, or a car that cut in. I knew I shouldn't, but I couldn't control it." But then he came to his senses, thinking of his youngest son left alone. "My son entered middle school two years after the accident, and that was when I realized I should snap back because being like this would make me lose my son as well." However, he claimed he could not completely overcome the psychological shock even after more than 10 years. "I can't sleep even after taking sleeping pills. I go to sleep at five in the morning, even now" (Lee 2014b).

"The injured received temporary support after the disaster, but they cannot easily visit a doctor even when they get ill due to financial difficulty. There are 146 injuries ( 5 deaths) as of today from the Daegu subway fire in 2013, and over 700 people, including the families, are suffering from the aftereffects. We never know when PTSD will occur to the injured and the families". (The Hankook Ilbo 2014)

"Six of the survivors are struggling against all kinds of cancer like gastric cancer, pancreatic cancer (two persons), laryngeal cancer, cervical cancer, and hematologic tumor. At first there were many views that the toxic gases would cause cancer, but after over 10 years, 10 cancer patients have been discovered, and some others we probably couldn't find out about. We're 
worried that the cancer may be an aftereffect of the accident, but there's no investigation of all the injured people, so we're living each and every day in anxiety". (MaeilShinmun 2017)

Moreover, due to the government's temporary compensation, the victims will not receive long-term treatment support for related cancer or illness. Furthermore, the local government pressed charges on the bereaved families for illegal burial when they buried the ashes of 32 victims at the Daegu Safety Theme Park created by the bereaved families on the Palgongsan Mountain in 2009. The bereaved families argued that Daegu agreed to the natural burials at the theme park and were ultimately found not guilty by the Supreme Court. The local government's behavior toward the bereaved families socially alienated them (Park 2018).

\subsubsection{Disaster Preparedness}

The victims and bereaved families of the Daegu subway fire launched a foundation to support the disaster victims, community, and citizens, acknowledging the sacrifices made by victims during the disaster on 18 February 2003.

"There was no friendly help extended to the suffering victims, and we just spent all the years helplessly without learning or gaining anything from the disaster", said the chairman of the foundation, Tae-il Kim, recalling the difficulties faced in the process of establishment. "We can't just hold on to the past. We should reconstruct the memories and move forward into the future. I hope the city of Daegu establishes itself as an emblem of safety and life by overcoming the painful history of 2003". (Cho 2016)

The disaster preparedness community of the Daegu subway fire survivors and bereaved families promotes resilience and serves as a key motivator. Following the disaster, the bereaved families gathered together and established the 2.18 Foundation for Safety Culture on December 24, 2010. This foundation was launched to fulfill the wishes of disaster survivors, the community, and citizens so as not to let the losses of the Daegu subway fire be ignored. The foundation's vision is "to create a safe world with our own hands," thus fulfilling its role as a primary agent for disaster preparedness in four areas (2.18 Foundation for Safety Culture 2018a).

Accordingly, as illustrated in Figure 3, the first area is memory. The 2.18 Foundation for Safety Culture claims that we can only create a safe future by remembering the catastrophes we have suffered in the past. Thus, the foundation fulfills the role of bringing back and reconstructing the memories of the disaster by carrying out various commemoration projects. Specific programs include holding the 2.18 memorial ceremony, establishing memorial facilities (parks, memorial tower, memorial cemetery park), building an archive, using Jungangno Station (memory space), running a safety week, and carrying out scholarship and welfare projects (2.18 Foundation for Safety Culture 2015).

The second area is healing. This is to heal the indelible wounds embedded in the hearts of disaster survivors. The foundation encourages various programs for victims' trauma recovery, which include uplifting the healing programs, recording the contact information of the bereaved families, facilitating empathy from the community for trauma recovery, and institutionalizing trauma centers (2.18 Foundation for Safety Culture 2018b).

The third area is growth. The foundation carefully considers how to face the suffering of the past and how to create a safe world by overcoming the pain. We can achieve growth by perceiving the terrible misfortunes we have experienced as organizational problems of our society instead of personally grieving, regretting, and being enraged by them. Disaster survivors, bereaved families, and the foundation promote safety culture education to unify people in thinking that protecting safety and lives is not made possible merely through individual efforts, but must also be facilitated through the cooperative efforts of society, the nation, and community. In light of this, the foundation carries out a safety culture instructor training program, the creation of safety maps using a smartphone application, and a subway safety culture campaign (2.18 Foundation for Safety Culture 2018b). 


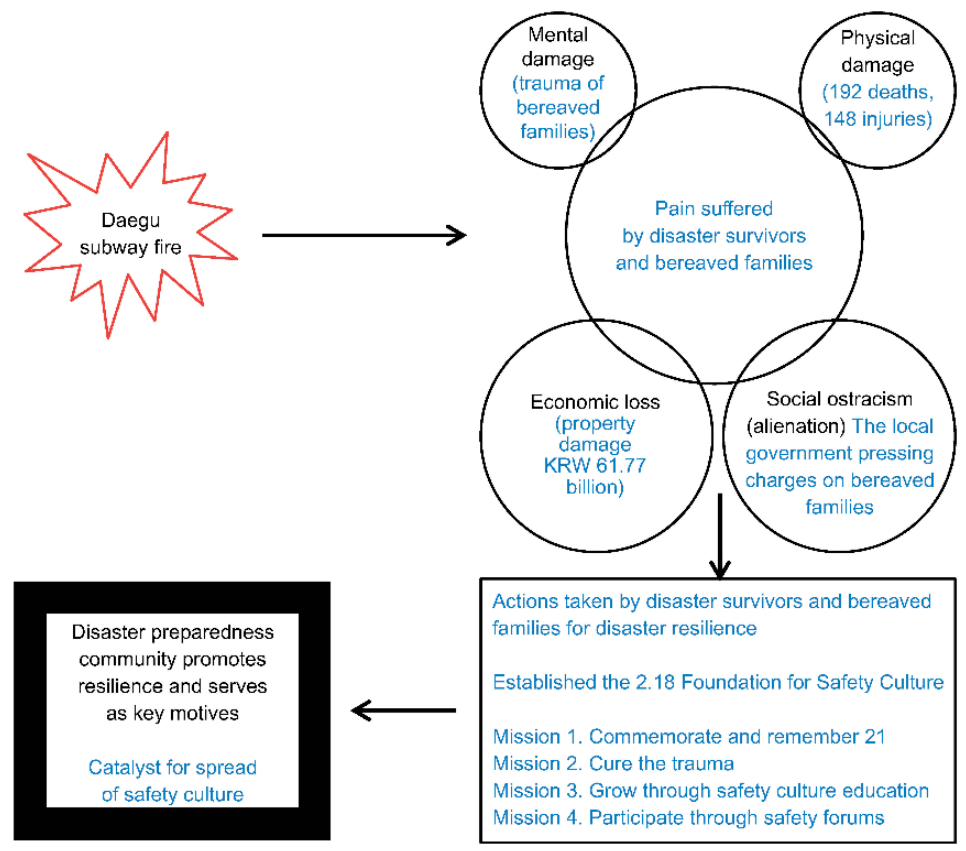

Figure 3. Disaster preparedness framework of disaster survivors and bereaved families for the Daegu subway fire.

The fourth area is participation. The foundation claims that we must act "to create a safe world with our own hands." Victims that suffered in the disaster as well as the general community must participate together. Protecting human lives and safety from disasters is a fundamental task that must be performed by the nation, but it is not something that can be done by the nation alone. Disaster management is largely dependent on social cooperation and the role of the community due to urgency and diversity. To this end, the foundation offers various forums, seminars, and round-table conferences to share research on safety, writing, and publications (2.18 Foundation for Safety Culture 2018b).

The 2.18 Foundation for Safety Culture secures the legitimacy of the effectiveness of disaster preparedness through qualitative and quantitative assessments of their projects through annual evaluation. Its functions as the primary agent of disaster preparedness, as indicated in its 2018 White Paper on Activities, are as follows: In the qualitative aspect, the foundation established the week encompassing February 18 (when the disaster occurred) as a safety week for Daegu citizens. During this week, the foundation communicated with citizens through various programs, alerted them to the disaster, reflected on the lessons learned, and collected data on the Daegu subway fire by building an archive. Moreover, the foundation worked towards building a rapport with victims by providing stabilized psychological support through proper perception and healing of trauma at trauma centers. Safety culture training was carried out in a total of 12 sessions, covering safety alertness, consciousness, and culture, as well disseminating a safety culture campaign throughout the community in association with the Daegu Traffic Broadcasting Network (TBN). In addition, the foundation provided an opportunity to assess safety in Daegu through the safety culture forum. In the quantitative aspect, the foundation implemented various activities for disaster preparedness and promoted communication with over 4600 citizens, disaster survivors, and bereaved families involved in related programs (2.18 Foundation for Safety Culture 2018b).

\subsection{Case Study 3: Sewol Ferry Disaster (4.16 Foundation)}

This tragic catastrophe occurred when the passenger ship Sewol (Cheonghaejin Marine Company) was en route from Incheon Coast Passenger Terminal on 15 April 2014 towards Jeju. The ferry sank in the waters near Byeongpung Island of Jindo-gun, Jeonnam on 16 April with 304 victims dead or 
missing. On board were 324 second-year students from Ansan Danwon High School who set out on a school trip to Jeju; many casualties were incurred among the young students (Jindo County 2017).

The Sewol began to sink from the portside, possibly due to rapid veering (quickly turning the wheel to change direction) at 8:49 a.m. on 16 April. However, the ferry's intercom system repeatedly ordered the passengers to "stay put" even while sinking, and there were no rescue operations. The Sewol ferry disaster marked one of the worst man-made disasters, with poor measures overall, such as delays in the initial response due to inadequate communication, the irresponsibility of the captain and the crew, passive rescue operations by the maritime police, and belated measures taken by the government (Jindo County 2017).

\subsubsection{Risk Perception}

On 14 January 2019, the Civil District Court 1 in the Ansan Branch of Suwon District Court (presiding judge and chief judge, Joo-cheol Son) decided in favor of the 76 survivors and bereaved families of the Sewol ferry disaster, who sued the government and Cheonghaejin Marine for damages. At the time, 16 Danwon High School students and 3 adults participated as the plaintiffs" (Lee 2019).

The court decided that it was illegal for the maritime police not to direct the Sewol passengers to leave the ship, and for the captain and crewmen of the Sewol ferry to leave immediately without proper relief work. Furthermore, this illegal act has a causal relation to mental pain suffered by survivors and families, such as PTSD, depression, and anxiety disorders. The court claimed, "The survivors faced great difficulty in the process of belatedly escaping the ship without receiving information or guidance to leave the ship, and thus suffered in fear for a long time in the submerged Sewol ferry"(Lee 2019).

Accordingly, as illustrated in Figure 4, the court pointed out that the government did not provide accurate information after the disaster, and even caused "secondary damage" by announcing victim support measures without consulting the victims. "The government caused confusion by not providing accurate rescue or search information and not taking proper measures to control the site," the court found. "Without providing systematic medical, psychological, and social support that reflects the opinions of victims and families, the government announced or advertised the support measures in advance without consultation, thereby exposing the plaintiffs to secondary damage"(Lee 2019).

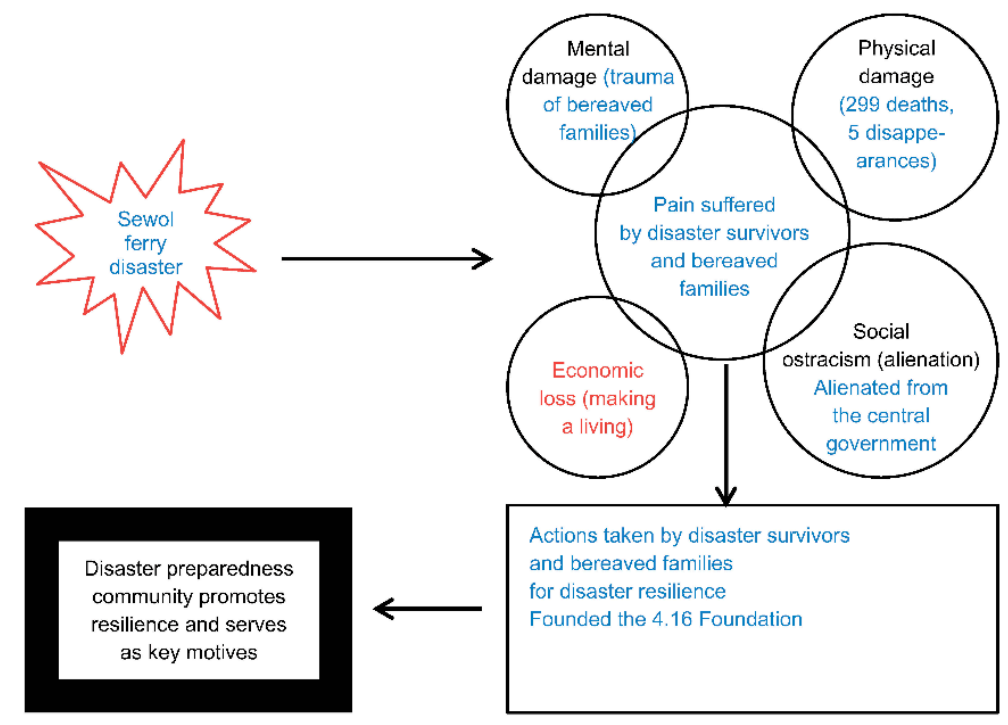

Figure 4. Disaster preparedness framework of disaster survivors and bereaved families for the Sewol Ferry disaster. 
In 2015, the Park Geun-hye administration announced an unprecedented amount of compensation worth millions of won (several hundred dollars) without consulting the survivors and families who were demanding accountability and an explanation. This led to the so-called "binge strike" of Ilbe members, insulting and disparaging the victims (Lee 2019).

\subsubsection{Disaster Preparedness}

Following the disaster, 145 bereaved families collected KRW 5 million each to set up a fund of KRW 725 million, establishing the 4.16 Foundation in March 2018. With the vision of creating a safe society for children, this foundation aims to investigate the truth behind the event, regain the victims' honor, support the construction of a safe society, turn the Life Safety Park into a global park, lay the groundwork for healing and livelihood support of victims, and build and expand sustainable solidarity (4.16 Foundation 2020).

The disaster preparedness community of the Sewol ferry disaster survivors and bereaved families promote resilience, which serves as their key motivator.

The 4.16 Foundation is the most recently established disaster-related foundation and, thus, has not implemented a great many activities and projects thus far. However, it has undertaken various activities and programs to overcome disaster trauma and to prepare for future disasters, as have the Korea Children Safety Foundation and the 2.18 Foundation for Safety Culture. The foundation actively holds international forums to support and reinforce the rights of disaster survivors, invites public participation in cultural contents, conducts research to lay the groundwork for a safe society, and has designed the 4.16 Life Safety Park (4.16 Foundation 2020).

\section{Limitations}

This study has the following limitations. First, of the many variables of community resilience, this study focused only on the participation of disaster victims among the participation of private organizations. There is a need to explore various variables that influence this in the future. Second, the subjects of this study (disaster victims) are limited to Koreans of specific disaster cases. Because research on disaster resilience of the community has a worldwide impact, there is a need to examine various countries, types of disaster, victims, and private organizations, and compare the results in the future.

\section{Discussion}

Although disaster preparedness is crucial for families, businesses, and communities, many people remain unprepared. Since 2005, communities began emphasizing the importance of individual responsibility, regional adjustment, and continuous planning for disaster preparedness to ensure immediate response to and quick recovery from catastrophic events (Sutton and Tierney 2006; Kato and Endo 2020).

This study identified the key roles in disaster preparedness of disaster survivors and bereaved families in Korea using case studies of successful networks that can serve as essential resources for disaster resilience. Three major disasters (Sealand fire, Daegu subway fire, and Sewol ferry disaster) were examined and perceived through the framework of disaster survivors and bereaved families that was derived directly from their direct and indirect pain and experience.

To play such a pivotal role, these foundations require collaboration between the community and government, as well as government support and public attention to strengthen disaster preparedness and for successful recovery efforts.

Thus far, disaster preparedness has been led by the national government and the community. However, the national government, local governments, communities, NGOs, and individuals must all work together to ensure efficient disaster preparedness. Specifically, individuals and families who have experienced the trauma of a disaster tend to absorb more information about disasters, thereby exerting influence over implementation for better disaster preparedness (Troy et al. 2008; Najafi et al. 2015). 
Studies on disaster survivors and bereaved families have focused predominantly on factors related to damage from the perspective of victims (Roysircar et al. 2019; Eriksen 2017; North et al. 2019; Morgado 2018) or on resilience (Robinson et al. 2017; Grolnick et al. 2018). Research has yet to be conducted on how disaster survivors and bereaved families prepare for disasters. This study examined the role of disaster survivors and bereaved families as the central figures in disaster preparedness in a community, beyond being mere victims of disasters.

The results of the three case studies examined reveal that disaster preparedness foundations established by victims and their families facilitate projects to help disaster survivors overcome psychological and physical trauma, offer scholarships to students to compensate for economic loss, hold various programs to overcome social ostracism, and produce valid qualitative and quantitative results.

In particular, the central government should establish a pathway for local communities to actively participate in disaster risk reduction and management, and through this steer the direction of national disaster management governance advocated by the Sendai Framework (González-Riancho et al. 2017; Godsoe et al. 2019; Merrin-Davies 2018; Pilli-Sihvola et al. 2018).

In Korea, the national assembly and the administration have reformed the "Framework Act on the Management of Disasters and Safety" based on the Hyogo Framework over a period of 10 years from 2005 to 2015, while establishing measures such as enforcement ordinances and rules to enhance the capabilities of the central government ministries and reviewing the individual laws related to disaster safety to strengthen the regional and local governments.

In every country, disasters are an obstacle to sustainable growth. Since 2015, intergovernmental negotiations for the financing of challenges related to economic growth, climate change, and disaster risk reduction have enabled the international community to enhance consistency between policies while respecting the obligations of the respective member counties, and providing opportunities for member counties to upgrade institutions, objectives, indicators, and measurement systems for their implementation. The UN Conference on Sustainable Development in 2012, entitled "The Future We Want," called for disaster risk reduction and the restoration of resilience. It reaffirmed the institution of an urgent response system to be integrated at all levels in the context of sustainable growth and hunger prevention (Leggett and Carter 2012).

For a safer region, the implementation of the Sendai Framework will be carried out in accordance with the following principles in reference to the Yokohama Strategy and the principles in the Hyogo Framework, and it will be based on the laws of each country, as well as international obligations, taking into account the circumstance of each country (Faivre et al. 2018; Burkle 2014; Sim et al. 2018).

Author Contributions: Conceptualization, S.A.K.; Data curation, S.A.K.; Formal analysis, S.A.K.; Funding acquisition, S.A.K.; Investigation, S.I.R.; Methodology, S.A.K. and S.I.R.; Project administration, S.A.K.; Resources, S.A.K.; Software, S.A.K.; Supervision, S.A.K.; Validation, S.I.R.; Visualization, S.A.K. and S.I.R.; Writing一original draft, S.A.K.; Writing-review \& editing, S.I.R. All authors have read and agreed to the published version of the manuscript.

Funding: This work was supported by the Ministry of Education of the Republic of Korea and the National Research Foundation of Korea (NRF-2017S1A5B8059946).

Conflicts of Interest: The authors declare no conflict of interest.

\section{References}

2.18 Foundation for Safety Culture. 2015. Vision and Goal. 2.18 Foundation for Safety Culture. Available online: http://www.218safety.com/content/01intro/02_01.php (accessed on 30 December 2019).

2.18 Foundation for Safety Culture. 2018a. White Paper on Activities. 2.18 Foundation for Safety Culture. Available online: http://www.218safety.com/content/01intro/05_01.php (accessed on 30 December 2019).

2.18 Foundation for Safety Culture. 2018b. Available online: http://www.218safety.com (accessed on 16 June 2020). 4.16 Foundation. 2020. Available online: http://416foundation.org (accessed on 16 June 2020). 
Abramson, David M., Tasha Stehling-Ariza, Yoon Soo Park, Lauren Walsh, and Derrin Culp. 2010. Measuring Individual Disaster Recovery: A Socioecological Framework. Disaster Medicine and Public Health Preparedness 4: S46-S54. [CrossRef]

Achoka, Judith S., and Julius Maiyo. 2008. Horrifying Disasters in Western Kenya; Impact on Education and National Development. Education Research Review 3: 154-61.

Adams, Richard E., and Joseph. A. Boscarino. 2006. Predictors of PTSD and Delayed PTSD after Disaster: The Impact of Exposure and Psychosocial Resources. Journal of Nervous and Mental Diseases 194: 485-93. [CrossRef] [PubMed]

Akbar, Muhammad Siddique, and Daniel P. Aldrich. 2017. Determinants of Post-flood Social and Institutional Trust among Disaster Victims. Journal of Contingencies and Crisis Management 25: 279-88. [CrossRef]

Akter, Shahriar, and Samuel Fosso Wamba. 2019. Big Data and Disaster Management: A Systematic Review and Agenda for Future Research. Annals of Operations Research 283: 939-59. [CrossRef]

Alexander, David A., and Susan Klein. 2009. First Responders after Disasters: A Review of Stress Reactions, At-Risk, Vulnerability, and Resilience Factors. Disaster Medicine 24: 87-94. [CrossRef] [PubMed]

Alexander, Bob, Catherine Chan-Halbrendt, and Wilmar Salim. 2006. Sustainable Livelihood Considerations for Disaster Risk Management: Implications for Implementation of the Government of Indonesia Tsunami Recovery Plan. Disaster Prevention Management 15: 31-50. [CrossRef]

Alfonso, César A. 2018. PTSD and Suicide after Natural Disasters. Psychiatric Times. April 24. Available online: https://www.psychiatrictimes.com/view/ptsd-and-suicide-after-natural-disasters (accessed on 16 June 2020).

Bajracharya, Bhishna, Iraphne Childs, and Peter Hastings. 2011. Climate Change Adaptation through Land Use Planning and Disaster Management: Local Government Perspectives from Queensland. Paper presented at the 17th Pacific Rim Real Estate Society Conference, Gold Coast, Australia, January 16-19; Gold Coast: Pacific Rim Real Estate Society.

Beck, Richard J., and Diane I Franke. 1996. Rehabilitation of Victims of Natural Disasters. Journal of Rehabilitation 62: 28.

Burkle, Frederick. M. 2014. Hyogo declaration and the cultural map of the world. Disaster Medicine and Public Health Preparedness 8: 280-82. [CrossRef]

Catherall, Don R. 2004. Handbook of Stress, Trauma, and the Family, 1st ed. New York: Brummer-Routledge.

Cho, Jung-Hoon. 2016. 13 Years of the Daegu Subway Disaster, '2.18 Safety and Culture Foundation' Opened. OhmyNews. September 7. Available online: http://www.ohmynews.com/NWS_Web/View/at_pg.aspx?CNT N_CD=A0002242277 (accessed on 30 December 2019).

Choi, Hoon Jin. 2018. 100\% Realization of Disaster...Songpa to Build Safe Muscle. The Seoul Shinmun. February 28. Available online: https://n.news.naver.com/article/081/0002896283 (accessed on 30 December 2019).

Col, Jeanne-Marie. 2007. Managing Disasters: The Role of Local Government. Public Administration Review 67: 114-24. [CrossRef]

Cui, Ke, and Ziqiang Han. 2019. Association between disaster experience and quality of life: The mediating role of disaster risk perception. Quality of Life Research 28: 509-13. [CrossRef] [PubMed]

Denborough, David, ed. 2006. Trauma: Narrative Responses to Traumatic Experience. Adelaide: Dulwich Centre Publications.

Department of Safety Culture Education, and Seulgi Lee. 2020. 2019 Safety Culture Best Practices. Ministry of Public Administration and Security. Publication, January 3. Available online: https://www.mois.go.kr/f rt/bbs/type001/commonSelectBoardArticle.do?bbsId=BBSMSTR_000000000012\&nttId=75132 (accessed on 10 June 2020).

Dhara, V., and Sushma Acquilla. 2012. Distance of Residence in 1984 May Be Used as Exposure Surrogate for the Bhopal Disaster. Indian Journal of Medical Research 136: 1060. [PubMed]

Duan, Taixiang, Hechao Jiang, Xiangshu Deng, Qiongwen Zhang, and Fang Wang. 2020. Government intervention, risk perception, and the adoption of protective action recommendations: Evidence from the COVID-19 prevention and control experience of China. International Journal of Environmental Research and Public Health 17: 3387. [CrossRef]

Eriksen, Christine. 2017. Research Ethics, Trauma and Self-Care: Reflections on Disaster Geographies. Australian Geographic 48: 273-78. [CrossRef] 
Faivre, Nicolas, Alessandra Sgobbi, Sander Happaerts, Julie Raynal, and Laura Schmidt. 2018. Translating the Sendai Framework into action: The EU approach to ecosystem-based disaster risk reduction. International Journal of Disaster Risk Reduction 32: 4-10. [CrossRef]

Figley, Charles R., and Hamilton I. McCubbin, eds. 1983. Stress and the Family. Vol. II. Coping with Catastrophe. New York: Routledge.

Gibbs, Lisa, Phoebe Quinn, David Johnston, Denise Blake, Emily Campbell, and Kate Brady. 2019. Recovery Capitals (ReCAP): Annual Report 2018-19. East Melbourne: Bushfire and Natural Hazards CRC.

Go, Un-ho. 2019. A Safe World for Children... 'Accident Response Manual' Released. The Chosun Ilbo. December 25. Available online: https://n.news.naver.com/article/023/0003495794 (accessed on 30 December 2019).

Godsoe, M., M. Ladd, and R. Cox. 2019. Assessing Canada's disaster baselines and projections under the Sendai Framework for Disaster Risk Reduction: A modeling tool to track progress. Natural Hazards 98: 293-317. [CrossRef]

Goidel, Kirby, Jennifer A. Horney, Paul M. Kellstedt, Emily Sullivan, and Stephanie E. Brown. 2019. Perceptions of Disaster Resilience in Four Texas Coastal Communities. Local Government Studies 45: 413-32. [CrossRef]

Goniewicz, Krzysztof, and Frederick M. Burkle. 2019. Challenges in implementing Sendai framework for disaster risk reduction in Poland. International Journal of Environmental Research and Public Health 16: 2574. [CrossRef]

González-Riancho, Pino, Birgit Gerkensmeier, and Beate MW Ratter. 2017. Storm surge resilience and the Sendai Framework: Risk perception, intention to prepare and enhanced collaboration along the German North Sea coast. Ocean \& Coastal Management 141: 118-31.

Goreham, Gary A., Deborah Bathke, Duane Gill, Daniel Klenow, Becky Koch, Kurt Mantonya, Ashley Mueller, Kalley Norr, Bimal K. Paul, Meredith Redlin, and et al. 2017. Successful Disaster Recovery Using the Community Capitals Framework: Report to the North Central Regional Center for Rural Development. May 31. Available online: https://www.ndsu.edu/fileadmin/socanth/Natural_Disaster_Recovery/Chapter_1_Intro duction_2_.pdf (accessed on 1 June 2020).

Government Finance Officers Association of the United States and Canada. 2008. Business Preparedness and Continuity Guidelines. Available online: https://www.gfoa.org/materials/business-preparedness-and-conti nuity-guidelines (accessed on 30 December 2019).

Grolnick, Wendy S., David J. Schonfeld, Merritt Schrieber, Judith Cohen, Valerie Cole, Lisa Jaycox, John Lochman, Betty Pfefferbaum, Kenneth Ruggiero, Kenneth Wells, and et al. 2018. Improving Adjustment and Resilience in Children Following a Disaster: Addressing Research Challenges. American Psychologist 73: 215-29. [CrossRef]

Hemingway, Laura, and Mark Priestley. 2006. Natural Hazards, Human Vulnerability and Disabling Societies: A Disaster for Disabled People? Available online: https://scholarspace.manoa.hawaii.edu/bitstream/10125/58 270/1/1037.pdf (accessed on 30 December 2019).

Hidayat, Benny, and Charles Egbu. 2010. A Literature Review of the Role of Project Management in Post-Disaster Reconstruction. Paper presented at 26th Annual ARCOM Conference, Leeds, UK, September 6-8; pp. 1269-78.

Hikichi, Hiroyuki, Jun Aida, Yusuke Matsuyama, Toru Tsuboya, Katsunori Kondo, and Ichiro Kawachi. 2020. Community-level Social Capital and Cognitive Decline after a Natural Disaster: A Natural Experiment from the 2011 Great East Japan Earthquake and Tsunami. Social Science and Medicine, 111981. [CrossRef] [PubMed]

Hong, Yong-deok. 2017. Bereaved families visited the 18th anniversary of the Sealand disaster. The Hankyoreh, June 30. Available online: http://www.hani.co.kr/arti/area/area_general/800940.html (accessed on 16 June 2020).

Jindo County, South Jeolla Province. 2017. White Paper on the 4.16 Year-Old Sewol Tragedy. Available online: http://www.archives.go.kr/next/search/showDetailPopup.do?rc_code=1310377\&rc_rfile_no=20180 8353475\&rc_ritem_no (accessed on 16 June 2020).

Joakim, Erin P., and Susan K. Wismer. 2015. Livelihood Recovery after Disaster. Development in Practice 25: 401-18. [CrossRef]

Johnson, Cassidy. 2007. Impacts of Prefabricated Temporary Housing after Disasters: 1999 Earthquakes in Turkey. Habitat International 31: 36-52. [CrossRef]

Kato, Takaaki, and Aiko Endo. 2020. Involving Citizens in Sharing Disaster Experiences across Areas: An Investigation into Disaster-stricken Communities and Observing Communities. International Journal of Disaster Risk Reduction 42: 101378. [CrossRef] 
KBS News. 2015. [Issue \& Talk] Sewol Issue 1st Period... What is the Current Status of 'Safety Awareness'? KBS News. April 15. Available online: https://n.news.naver.com/article/056/0010156795 (accessed on 30 December 2019).

Khan, M. Shah Alam. 2008. Disaster Preparedness for Sustainable Development in Bangladesh. Disaster Prevention and Management 17: 662-71. [CrossRef]

Kiliç, Emine Zinner, Halise Devrimci Özgüven, and Iaik Sayil. 2003. The Psychological Effects of Parental Mental Health on Children Experiencing Disaster: The Experience of Bolu Earthquake in Turkey. Family Process 42: 485-95. [CrossRef]

Kim, Tae-Hwan. 2006a. Disaster prevention: Sealand fire. Ministry of Public Administration and Security's National Archives of Korea. December 1. Available online: http://www.archives.go.kr/next/search/listSubjectDescriptio n.do?id=001919\&sitePage=1-2-3 (accessed on 30 December 2019).

Kim, Tae-Hwan. 2006b. Disaster prevention: Daegu subway fire accident. Ministry of Public Administration and Security's National Archives of Korea, December 1. Available online: http://www.archives.go.kr/next/se arch/listSubjectDescription.do?id=001920\&subjectTypeId=06\&pageFlag=C\&sitePage=1-2-2 (accessed on 30 December 2019).

Kim, So-jung. 2019. YouTuber Crosses the Line in Disparaging the Sewol Ferry Victims: "School Trip Mocked as a Water Trip". Dong-A Daily News. January 23. Available online: http://www.donga.com/news/article/all/20190 123/93826230/2 (accessed on 16 June 2020).

Korea Children Safety Foundation. 2017. Available online: http://www.childsafe.or.kr (accessed on 16 June 2020).

Korol, Mindy, Bonnie L. Green, and Goldine C. Gleser. 1999. Children's Responses to a Nuclear Waste Disaster: PTSD Symptoms and Outcome Prediction. Journal of the American Academy of Child E Adolescent Psychiatry 38: 368-75. [CrossRef]

Kusumasari, Bevaola, Quamrul Alam, and Kamal Siddiqui. 2010. Resource Capability for Local Government in Managing Disaster. Disaster Prevention and Management 19: 438-51. [CrossRef]

Lechowska, Ewa. 2018. What determines flood risk perception? A review of factors of flood risk perception and relations between its basic elements. Natural Hazards 94: 1341-66. [CrossRef]

Lee, Ki-Beom. 2014a. [Sewol ferry disaster] "I tell you to forget, but I will not forget". Nocut News, April 28. Available online: https://n.news.naver.com/article/079/0002590281 (accessed on 30 December 2019).

Lee, Ki-Beom. 2014b. [Sewol ferry disaster] "After the funeral, pain begins". Nocut News. April 30. Available online: https://n.news.naver.com/article/079/0002591296 (accessed on 30 December 2019).

Lee, Changhoon. 2018. [My Life] "My dream is a world without the need for the Children's Safety Foundation". The Segye Times, May 19. Available online: https://n.news.naver.com/article/022/0003274752?lfrom=kakao (accessed on 16 June 2020).

Lee, Hye-ri. 2019. Court "State responsibility until the second damage to the Sewol tragedy survivors". Kyunghyang Shinmun, January 14. Available online: http://news.khan.co.kr/kh_news/khan_art_view.html?artid=2019011 41558001\&code $=940100$ (accessed on 30 December 2019).

Leggett, Jane A., and Nicole T. Carter. 2012. Rio+ 20: The United Nations Conference on Sustainable Development, June 2012. Washington, DC: Library of Congress, Congressional Research Service.

Lin, Pei-Shan Sonia. 2018. Building Resilience through Ecosystem Restoration and Community Participation: Post-Disaster Recovery in Coastal Island Communities. International Journal of Disaster Risk Reduction 39: 101249. [CrossRef]

Lin, Yiwen, Mihaela Kelemen, and Toru Kiyomiya. 2017. The Role of Community Leadership in Disaster Recovery Projects: Tsunami Lessons from Japan. International Journal of Project Management 35: 913-24. [CrossRef]

Lo, Alex, and Lewis T. O. Cheung. 2016. Geographies of social capital: Catastrophe experience, risk perception, and the transformation of social space in post-earthquake resettlements in Sichuan, China. Annals of the American Association of Geographers 106: 874-90. [CrossRef]

MaeilShinmun, The. 2017. Subway disaster injured, unending pain. The MaeilShinmun, February 14. Available online: https://n.news.naver.com/article/088/0000480097 (accessed on 30 December 2019).

Manyena, Bernard, Geoff O’Brien, Phil O'Keefe, and Joanne Rose. 2011. Disaster Resilience: A Bounce Back or Bounce Forward Ability? Local Environment 16: 417-24. [CrossRef]

Marsh, Graham, Iftekhar Ahmed, Martin Mulligan, Jenny Donovan, and Steve Barton. 2017. Community Engagement in Post-Disaster Recovery. Abingdon: Routledge. 
Masud-All-Kamal, M. 2013. Livelihood Coping and Recovery from Disaster: The Case of Coastal Bangladesh. Current Research Journal of Social Sciences 1: 35-44. [CrossRef]

Merrin-Davies, Maddison. 2018. Implementation of the Sendai framework for disaster risk reduction in Australia. The Australian Journal of Emergency Management 33: 5.

Mishra, Sasmita, and Damodar Suar. 2007. Do Lessons People Learn Determine Disaster Cognition and Preparedness? Psychology and Developing Societies 19: 143-59. [CrossRef]

Mohebbi, Hassan Ali, Shaban Mehrvarz, Masoud Saghafinia, Yadollah Rezaei, Seyed. Mohsen Towliat. Kashani, Seyed Morteza Moussavi Naeeni, Mohammad Hosein Kalantar Motamedi, Seyed Hamed Hoseini, and Yashar Moharamzad. 2008. Earthquake Related Injuries: Assessment of 854 Victims of the 2003 Bam Disaster Transported to Tertiary Referral Hospitals. Prehospital Disaster Medicine 23: 510-15. [CrossRef]

Morgado, A. M. 2018. After Disaster: Conceptualising the Extent and Length of the Psychological Impact. BMC Health Services Research, 481-89.

Mudavanhu, Chipo, Siambalala Bernard Manyaena, Andrew E. Collins, Paradzayi Bongo, Emmanuel Mavhura, and Desmond Manatsa. 2015. Taking Children's Voices in Disaster Risk Reduction a Step Forward. International Journal of Disaster Risk Reduction 6: 267-81. [CrossRef]

Najafi, Mehdi, Ali Ardalan, Ali Akbarisari, Ahmad Ali Noorbala, and Hossain Jabbari. 2015. Demographic Determinants of Disaster Preparedness Behaviors amongst Tehran Inhabitants, Iran. PLoS Currents Disasters 7. [CrossRef]

Norris, Fran H., Matthew J. Friedman, Patricia J. Watson, Christopher M. Byrne, Eolia Diaz, and Krzysztof Kaniasty. 2002a. 60,000 Disaster Victims Speak: Part I. An Empirical Review of the Empirical Literature, 1981-2001. Psychiatry Interpersonal and Biological Processes 65: 207-39. [CrossRef] [PubMed]

Norris, Fran H., Matthew J. Friedman, and Patricia J. Watson. 2002b. 60,000 Disaster Survivors and Bereaved Families Speak: Part II. Summary and Implications of the Disaster Mental Health Research. Psychiatry: Interpersonal and Biological Processes 65: 240-60. [CrossRef] [PubMed]

North, Carol S., Aya Kawasaki, Edward L. Spitznagel, and Barry A. Hong. 2004. The Course of PTST, Major Depression, Substance Abuse, and Somatization after a Natural Disaster. Journal of Nervous and Mental Disorders 192: 823-29. [CrossRef] [PubMed]

North, Carol S., Erin Van Enkevort, Barry A. Hong, and Alina M. Suris. 2019. Association of PTSD Symptom Groups with Functional Impairment and Distress in Trauma-exposed Disaster Survivors. Psychological Medicine 50: 1556-62. [CrossRef]

Ollendick, Duane G., and Sister Margeen Hoffmann. 1982. Assessment of Psychological Reactions in Disaster Victims. Journal of Community Psychology 10: 157-67. [CrossRef]

Onuma, Hiroki, Kong Joo Shin, and Shunsuke Managi. 2017. Household Preparedness for Natural Disasters: Impact of Disaster Experience and Implications for Future Disaster Risks in Japan. International Journal of Disaster Risk Reduction 21: 148-58. [CrossRef]

Park, Myung-han. 2018. The 15th Anniversary of the Daegu Subway Disaster. BBS News, February 18. Available online: http://news.bbsi.co.kr/news/articleView.html?idxno=866883 (accessed on 30 December 2019).

Park, Chae-young. 2019. Sewol Families Sue Prosecutors of Ilbe Members. Kyunghyang Shinmun, June 24. Available online: http://news.khan.co.kr/kh_news/khan_art_view.html?artid=201906241431001\&code=9403 01 (accessed on 16 June 2020).

Paton, Douglas. 2006. Disaster Resilience: Integrating Individual, Community, Institutional, and Environmental Perspectives. In Disaster Resilience: An Integrated Approach. Edited by Douglas Paton and David Johnston. Springfield: Charles C. Thomas, pp. 305-18.

Piccardi, Laura, Maddalena Boccia, Stefano Colangeli, Filippo Bianchini, Assunta Marano, Anna Maria Giannini, Massimiliano Palmiero, and Simonetta D'Amico. 2016. Neuro-functional Alterations Due to PTSD after Environmental Disasters: fMRI Evidence and Clinical Suggestions. Journal of Psychopathology 22: 165-71. [CrossRef]

Pilli-Sihvola, Karoliina, Atte Harjanne, and Riina Haavisto. 2018. Adaptation by the least vulnerable: Managing climate and disaster risks in Finland. International Journal of Disaster Risk Reduction 31: 1266-75. [CrossRef]

Prewitt Diaz, Joseph O. 2018. Disaster Recovery: Community-Based Psychosocial Support in the Aftermath. Boca Raton: CRC Press. 
Prior, Tim, and Florian Roth. 2019. Resilience to Disaster is No Small Measure. CSS Analyses in Security Policy. May. Available online: https://css.ethz.ch/content/dam/ethz/special-interest/gess/cis/center-for-securities-stu dies/pdfs/CSSAnalyse245-EN.pdf (accessed on 1 August 2020).

Rao, Sumedh. 2013. Disaster risk governance at national and sub-national levels (Vol. 991). GSDRC Helpdesk Research Report. Available online: http://gsdrc.org/docs/open/hdq991.pdf (accessed on 1 August 2020).

Raphael, Beverly. 1986. When Disaster Strikes: How Individuals and Communities Cope with Catastrophe. New York: Basic Books.

Reinhardt, Jan D., Jianan Li, James Gosney, Farooq A. Rathore, Andrew J. Haig, Michael Marx, Joel A. Delisa, and on behalf of the International Society of Physical and Rehabilitation Medicine's Sub-Committee on Rehabilitation Disaster Relief. 2011. Disability and Health-Related Rehabilitation in International Disaster Relief. Global Health Action 4: 7191. [CrossRef]

Robinson, Scott E., Warren S. Eller, Melanie Gall, and Brian J. Gerber. 2017. The Core and the Periphery of Emergency Management Networks: A Multi-Modal Assessment of Two Evacuation-Hosting Networks from 2000 to 2009. In Disaster and Crisis Management: Public Management Perspectives. Edited by Naim Kapucu and Arjen Boin. Abingdon: Routledge, pp. 334-62.

Ross, Ashley D. 2013. Local Disaster Resilience: Administrative and Political Perspectives. Abingdon: Routledge.

Roysircar, Gargi, Kurt F. Geisinger, and Ashland Thompson. 2019. Haitian Children's Disaster Trauma: Validation of Pictorial Assessment of Resilience and Vulnerability. Journal of Black Psychology 45: 269-305. [CrossRef]

Shapira, Stav, Limor Aharonson-Daniel, and Yaron Bar-Dayan. 2018. Anticipated behavioral response patterns to an earthquake: The role of personal and household characteristics, risk perception, previous experience and preparedness. International Journal of Disaster Risk Reduction 31: 1-8. [CrossRef]

Shaw, Rajib, and Katsuihciro Goda. 2004. From Disaster to Sustainable Civil Society: The Kobe Experience. Disasters 28: 16-40. [CrossRef] [PubMed]

Sim, Timothy, Dongming Wang, and Ziqiang Han. 2018. Assessing the disaster resilience of megacities: The case of Hong Kong. Sustainability 10: 1137. [CrossRef]

Sutton, Jeannette, and Kathleen Tierney. 2006. Disaster Preparedness: Concepts, Guidance, and Research. Paper presented at the Fritz Institute Assessing Disaster Preparedness Conference, Sebastopol, CA, USA, November $3-4$; pp. 1-41.

The Hankook Ilbo. 2014. Daegu subway tragedy injured suffer from one-off compensation. The Hankook Ilbo, June 10. Available online: https://n.news.naver.com/article/469/0000001680 (accessed on 30 December 2019).

Tiepolo, Maurizio, and Sarah Braccio. 2020. Mainstreaming Disaster Risk Reduction into Local Development Plans for Rural Tropical Africa: A Systematic Assessment. Sustainability 12: 2196. [CrossRef]

Tierney, Kathleen. 2012. Disaster governance: Social, political, and economic dimensions. Annual Review of Environment and Resources 37: 341-63. [CrossRef]

Troy, Douglas A., Anne Carson, Jean Vanderbeek, and Anne Hutton. 2008. Enhancing Community-Based Disaster Preparedness with Information Technology. Disasters 32: 149-65. [CrossRef] [PubMed]

United Nations Office for Disaster Risk Reduction. 2005. Building the resilience of nations and communities to disasters: Hyogo Framework for Action 2005-2015. Available online: http://www.unisdr.org/wcdr/intergov er/official-doc/Ldocs/Hyogo-framework-for-action-english.pdf (accessed on 30 December 2019).

United Nations Office for Disaster Risk Reduction. 2020. What is the Sendai Framework for Disaster Risk Reduction? Available online: https://www.undrr.org/implementing-sendai-framework/what-sendai-framew ork (accessed on 23 September 2020).

Walsh, Froma. 2007. Traumatic Loss and Major Disasters: Strengthening Family and Community Resilience. Family Process 46: 207-227. [CrossRef]

Walter, Jonathan. 2004. World Disasters Report 2004: Focus on Community Resilience. Geneva: International Federation of Red Cross and Red Crescent Societies.

Webb, Nancy Boyd, ed. 2003. Mass Trauma and Violence: Helping Families and Children Cope. New York: Guilford Press.

Wilkin, Joanna, Eloise Biggs, and Andrew J. Tatem. 2019. Measurement of Social Networks for Innovation within Community Disaster Resilience. Sustainability 11: 1943. [CrossRef]

Xu, Dingde, Linmei Zhuang, Xin Deng, Cheng Qing, and Zhuolin Yong. 2020. Media exposure, disaster experience, and risk perception of rural households in earthquake-stricken areas: Evidence from rural China. International Journal of Environmental Research and Public Health 17: 3246. [CrossRef] 
Yoon, Hong-jib. 2019. The Family of the Sewol Ferry, Park Geun-Hye, Hwang Gyo-An, etc. Accused “Unwritten and Intentional Murder". Available online: https://www.fnnews.com/news/201911151733305188 (accessed on 16 June 2020).

Yule, William, Derek Bolton, Orlee Udwin, Stephanie Boyle, Dominic O’Ryan, and Julie Nurrish. 2000. The Long-Term Psychological Effects of a Disaster Experienced in Adolescence: I: The Incidence and Course of PTSD. Journal of Child Psychology and Psychiatry 41: 503-11. [CrossRef]

Publisher's Note: MDPI stays neutral with regard to jurisdictional claims in published maps and institutional affiliations.

(C) 2020 by the authors. Licensee MDPI, Basel, Switzerland. This article is an open access article distributed under the terms and conditions of the Creative Commons Attribution (CC BY) license (http://creativecommons.org/licenses/by/4.0/). 